\title{
A experiência do HCFMUSP no atendimento a pacientes com COVID-19
}

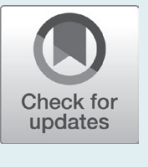

\author{
Beatriz Perondi ${ }^{1}$, Anna Miethke-Morais ${ }^{2}$, Leila Suemi Harima ${ }^{3}$, Amanda Cardoso Montal ${ }^{4}$, \\ Edivaldo Massazo Utiyama ${ }^{5}$, Aluísio Augusto Cotrim Segurado ${ }^{6}$, Eloisa Bonfá 7
}

DOI: https://doi.org/10.46833/reumatologiasp.2020.19.3.43-45

\begin{abstract}
Resumo Para planejar-se diante da emergência da infecção por COVID-19 na China, que viria a se tornar uma pandemia com imensa demanda dos serviços de saúde, o Hospital das Clínicas da Faculdade de Medicina da Universidade de São Paulo (HCFMUSP) ativou precocemente o seu plano de desastres e, como resposta, posteriormente isolou seu maior instituto, com 900 leitos, para que ficasse exclusivamente dedicado ao atendimento de pacientes de COVID-19. Esse processo envolveu a transferência de pacientes e serviços (unidades de internação e de emergência) para os outros institutos, que desta forma puderam manter o atendimento às patologias terciárias não relacionadas à COVID-19 nas áreas assim chamadas de baixa exposição. Um dos aspectos mais desafiadores foi a expansão de capacidades de leitos de UTI, que foi de 94 para 300 em dois meses. Além dos aspectos estruturais que precisaram ser contornados, a disponibilidade de profissionais com competência técnica para atuar em terapia intensiva só foi possível com a atuação de anestesistas, disponíveis no pico da crise pela redução de procedimentos eletivos, $e$ da parceria com empresas e hospitais privados, que contribuíram financeiramente e com suas equipes para possibilitar essa expansão. Para os colaboradores, muitos deles atuando fora de suas especialidades habituais, foram criados treinamentos presenciais e a distância, canais de divulgação de protocolos de tratamento, bem como canais de apoio psicológico. Como resultado da mobilização do HCFMUSP, obtivemos, até o início de agosto, mais de 4 mil internações relacionadas à COVID-19, a maior parte de pacientes graves, com passagem por UTI e altas taxas de ventilação mecânica e necessidade de hemodiálise. $O$ isolamento do Instituto Central do Hospital das Clínicas (ICHC) permitiu também a manutenção de uma parcela significativa do atendimento NÃO-COVID, como procedimentos cirúrgicos, que se mantiveram em funcionamento nos institutos de baixa exposição.
\end{abstract}

Unitermos COVID-19. Pandemia. Gerenciamento de crises. Sars-CoV-2.

1. MD, MBA, coordenadora de Gestão Assistencial Corporativa da Diretoria Clínica do Hospital das Clínicas da Faculdade de Medicina da Universidade de São Paulo (HCFMUSP), São Paulo-SP, Brasil.

2. MD, MBA, vice-coordenadora de Gestão Assistencial Corporativa da Diretoria Clínica do Hospital das Clínicas da Faculdade de Medicina da Universidade de São Paulo (HCFMUSP), São Paulo-SP, Brasil.

3. MD, MBA, coordenadora de Informática Assistencial da Diretoria Clínica do Hospital das Clínicas da Faculdade de Medicina da Universidade de São Paulo (HCFMUSP), São Paulo-SP, Brasil.

4. MD, MBA, diretora da Unidade de Emergência Referenciada do Instituto Central do Hospital das Clínicas (ICHC) da Faculdade de Medicina da Universidade de São Paulo (HCFMUSP), São Paulo-SP, Brasil.

5. Professor titular e vice-diretor clínico do complexo Hospital das Clínicas da Faculdade de Medicina da Universidade de São Paulo (HCFMUSP), São Paulo-SP, Brasil.
6. Professor titular, presidente do Conselho Diretor do Instituto Central do Hospital das Clínicas (ICHC) da Faculdade de Medicina da Universidade de São Paulo (HCFMUSP), São Paulo-SP, Brasil.

7. Professora titular e diretora clínica do Complexo Hospital das Clínicas da Faculdade de Medicina da Universidade de São Paulo (HCFMUSP), São Paulo-SP, Brasil.

Correspondência: Prof.a Dra. Eloisa Bonfá,

e-mail: eloisa.bonfa@hc.fm.usp.br.

Como citar este artigo: Perondi B, Miethke-Morais A, Harima LS, Montal AC, Utiyama EM, Segurado AAC, Bonfá E. A experiência do HCFMUSP no atendimento a pacientes com COVID-19. Rev Paul Reumatol. 2020 jul-set;19(3):43-5. DOI: https://doi.org/10.46833/ reumatologiasp.2020.19.3.43-45.

Os autores não contaram com apoio financeiro.

Os autores declaram não ter interesses associativos, comerciais, de propriedade ou financeiros que representem conflito de interesse nos produtos e empresas descritos neste artigo. 
A história do complexo Hospital das Clínicas da Faculdade de Medicina da Universidade de São Paulo (HCFMUSP) com a síndrome respiratória aguda da COVID-19 se inicia em 29 de janeiro de 2020, quando foi ativado o plano de desastre utilizando um protocolo internacional denominado HICS (Hospital Command Incident System). Este protocolo é utilizado desde $2013 \mathrm{em}$ nossa instituição em situações de desastre ou nas quais se prevê que a demanda vai superar muito a nossa capacidade de oferta de serviço de Saúde. Este protocolo foi ativado pelo Comitê de Crise, constituído por três professores titulares (diretor e vice-diretor clínico e presidente do Conselho Diretor do Instituto Central do Hospital das Clínicas - ICHC) e quatro médicas gestoras e especialistas em crise da diretoria clínica.

No dia da ativação do protocolo HICS para a infecção por COVID-19 em nossa instituição, a doença estava limitada à região da China e tínhamos no mundo reportados 6.057 casos. Durante dois meses o Comitê de Crise focou no estabelecimento de fluxos, tendo como premissa que cada um dos oito institutos especializados do complexo HC teria a sua área COVID-19 isolada.

No dia 23 de março de 2020 já tínhamos reportado no mundo mais de 300 mil casos e a pandemia estava estabelecida, bem como o seu alto grau de contágio. Nesse dia optamos por isolar o ICHC, nosso maior instituto, com 900 leitos do total de 2.400 leitos do complexo HC, exclusivamente para o atendimento de pacientes com COVID-19. O Hospital Universitário (HU) da USP também foi convidado para fazer parte deste projeto e se manter com atendimento de pacientes NÃO-COVID, totalizando sete institutos e o HU, que permaneceriam de baixa exposição.

No período aproximado de uma semana fizemos os novos fluxos e o isolamento do ICHC com transferência de nossa Unidade de Emergência Referenciada e dos pacientes para outros institutos. Estabelecemos como premissas que todos os colaboradores estavam recrutados por decreto (os que apresentavam risco COVID-19 grave foram alocados para os institutos de baixa exposição) e que todas as clínicas teriam de estar representadas no ICHC e nos institutos de baixa exposição em que fossem atuar.

O impacto desta mobilização foi muito grande, exigindo o deslocamento do atendimento de emergências para outros três institutos e o $\mathrm{HU}$, sendo que o maior impacto foi no Instituto do Coração (INCOR), que se tornou a nossa porta de referenciamento, passando de uma Emergência especializada em Cardiologia e Pneumologia para uma Emergência geral acomodando a maioria das especialidades médicas de Emergência. Foi necessário manter também dentro do ICHC todas as especialidades médicas de Emergência para atendimento de pacientes com COVID-19.

Com relação ao atendimento NÃO-COVID, das mais de 30 diferentes clínicas que atuavam no ICHC, estas foram transferidas para as enfermarias de seis institutos, tendo o Instituto de Ortopedia recebido a maioria delas, inclusive a Reumatologia.

$\mathrm{O}$ atendimento ambulatorial foi postergado via telefone sempre que possível e mantidos apenas os casos mais graves. 0 Centro de Biológico, coordenado pela Reumatologia, foi mantido em funcionamento para os pacientes que em terapia requeriam tratamento endovenoso.
Rapidamente percebemos que a maior necessidade da rede de referenciamento de pacientes muito graves para o complexo HC desta doença eram leitos de UTIs. Desta forma tivemos que ampliar os nossos 94 leitos ativos para 200 e depois 300 . Este processo foi extremamente desafiador, considerando que nessa época existia uma escassez de profissionais capacitados para UTI no mercado e falta de ventiladores. Além disso, nossos valores pagos de plantões não eram competitivos no mercado e o ICHC não tinha a infraestrutura necessária para mais leitos de terapia intensiva, sendo necessária a ampliação da rede de gases de energia. A logística de compra e distribuição de equipamentos de proteção individual mereceu destaque no processo de organização e foi liderada pela superintendência.

Para superar as dificuldades em ter equipes capacitadas para atuar em UTI, optamos por recrutar anestesistas - categoria que estava subutilizada na pandemia devido ao cancelamento de cirurgias eletivas e que tinha competência para o uso de equipamentos de anestesia para ventilação invasiva. Estes profissionais foram convidados para trabalhar com equipes mistas com um especialista em terapia intensiva. A infraestrutura do Centro Cirúrgico ofereceu as melhores condições para a abertura de leitos de UTI, por sua infraestrutura com similaridade com UTIs, e com isso transformamos 34 salas cirúrgicas em 76 leitos de UTI.

Nas enfermarias que também tinham um perfil de pacientes muito graves foi necessário implantar monitoramento para acompanhamento dos pacientes. Além disso, precisamos fazer enfermarias especializadas para atender à necessidade da rede, tais como Obstetrícia, Psiquiatria, Pediatria, Oncologia, Hematologia e Paliativos.

A questão de competência técnica foi superada pela parceria com diversos hospitais privados (Sírio-Libanês, HCor, Beneficência Portuguesa, Rede D' Or e Albert Einstein), além da vinda de equipes do Grupo de Resgate e Atenção às Urgências e Emergências (GRAU) e da Associação de Assistência à Criança Deficiente (AACD). Tivemos ainda o apoio inestimável da iniciativa privada com muitas doações e particularmente a do BTG Pactual, que fez um consórcio de doações, que viabilizou a contratação rápida de anestesistas.

Organizamos as enfermarias em equipes de médicos com residentes, plantonistas e assistentes de especialidades não relacionadas com a COVID-19. Para cada equipe existiu um assistente de referência especializado responsável por quatro enfermarias. Para as UTIs utilizamos o mesmo conceito, porém o assistente era sempre um profissional com familiaridade com UTIs e que também tinham suporte de uma assistente especializado. Estas duas infraestruturas requereram adaptações, como utilização da área administrativa para serem utilizadas com vestiário, conforto médico e copas.

$\mathrm{O}$ funcionamento destas unidades teve o apoio de times de suporte que foram implantados para a agilidade do processo e complementação das competências das equipes que estavam atuando. Os times disponíveis para as equipes foram o de resposta rápida com anestesistas para intubação, transporte de paciente crítico, prona e úlcera de pressão, passagem de cateter, traqueostomia, diálise e paliativos. 
Outras iniciativas implantadas foram treinamento presencial em área de anfiteatro, que ficou destinada para esta finalidade, e vários tutoriais online feitos pelos nossos especialistas e disponibilizados para todos os colaboradores. Tivemos também treinamentos com simulação para a equipe multiprofissional, feitos com o apoio de nossa Escola de Educação Permanente (EEP) e do Hospital Sírio-Libanês. O Instituto de Psiquiatria fez diversas iniciativas de apoio aos colaboradores, incluindo um hotline de 24 horas que permitia o acesso por aplicativo de telefone celular. Oferecemos também acolhimento para os colaboradores que apresentavam sintomas, com uma central específica para esta finalidade que funcionou com a colaboração fundamental dos residentes e estagiários da Otorrinolaringologia, que atenderam mais de 7 mil colaboradores. Para os pacientes foi instituída a televisita, projeto liderado pelo grupo de humanização e paliativos, além de doação de empresas privadas.

Para superar as dificuldades de comunicação foi criado um canal de informes COVID na Web Institucional, complementado por visitas presenciais de um dos membros do Comitê de Crise nas diferentes alas. Foi ainda fundamental o papel do diretor da escola que liderou a comunicação externa com os professores titulares. Enfrentamos um número expressivo de liminares para afastamento de colaboradores.
Os resultados desta mobilização são, até o início de agosto, mais de 4 mil pacientes internados, sendo $60 \%$ em UTIs. O HC foi o hospital que mais recebeu pacientes da Rede Cross, sendo que metade foram para terapia intensiva. E refletindo o referenciamento terciário de pacientes graves, a frequência de intubação em nossas UTIs foi de $80 \%$, diálise $30 \%$ e prona $30 \%$.

O nosso projeto impactou também de forma positiva o atendimento NÃO-COVID mantido em sete institutos e o HU, os quais funcionaram como áreas de baixa exposição durante a pandemia. Foi possível acolher esta demanda de pacientes e os números mostram que a porcentagem de procedimentos cirúrgicos nos diferentes institutos foi expressiva e variou de $45-70 \%$ comparada ao ano anterior. 0 perfil de procedimentos foi dirigido às urgências/emergências. $\mathrm{Na}$ área de Obstetrícia tivemos inclusive um aumento de atendimentos comparados ao ano anterior, provavelmente refletindo uma dificuldade da rede em acolher este grupo de pacientes NÃO-COVID da rede.

Este projeto só foi possível com a colaboração, dedicação e profissionalismo dos mais de 7 mil colaboradores da linha de frente e os 13 mil das áreas de baixa exposição, além dos profissionais do HU. Temos um enorme orgulho de dizer que eles não recuaram e juntos enfrentaram a maior crise de luta pela vida que o complexo HC enfrentou nos seus 76 anos de vida. Valeu a pena! 